Journal of Mathematics and Statistics 5 (2):88-89, 2009

ISSN 1549-3644

(C) 2009 Science Publications

\title{
On Algebra and Tachyons
}

${ }^{1}$ M. Sivasubramanian and ${ }^{2} \mathrm{~S}$. Kalimuthu

${ }^{1}$ Department of Mathematics, Mahalingam College of Engineering and Tech

Udumalai Road, Pollachi, Tamil Nadu 642 003, India

${ }^{2}$ G.S. No. 212/4, Kajampatti P.O. Pollachi Via, Tamil Nadu-642 00

Abstract: Problem statement: After formulating the special theory of
Einstein politely remarked: "for velocities that are greater than light meaningless". In 1962, Sudarshan and his co-researchers proposed a hy whose rest mass is imaginary can travel by birth faster than light. Afte pu in of Sudarshour's research, many scholars began to probe into faster than light phenomen. In exto elativity, many properties of tachyons have been found. But still this micro second the velocity of a respect to us is unknown. In this research the researchers for velocity. Ap p ch: In this research, Einstein's variation of mass with velocity equatio is transformed into quadratic equation. We introduced a new hypothesis to find the roots of the qu atic equation. $y$ ults: By introducing a new hypothesis in tachyon algebra, the researchers found $t$ he velocity of erluminal objects with respect to us is $v=c \sqrt{3}$ where $c$ is the velocity of the ligh nclusion/Re imendations: But the road to tachyon is too long. Hereafter it is up to existence/generation of tachyons.

Key words: Einstein, special theory of relat quadratic equations and new conje

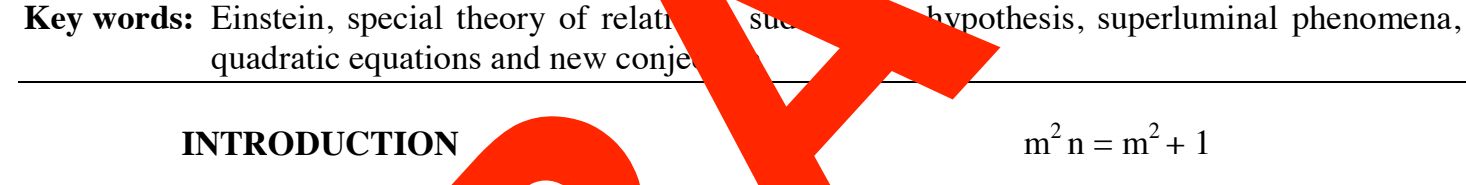

Algebra is one of the most $p$ other branches of mathemati application of modern algehra c.
impossible to solve the sus ch problems trisection of a general a with out us 'otractor, squaring the circle, $d$ the cube ano aw a regular septagon ${ }^{[2]}$ tudy, the res, archers introduced a new onjectur quadratic equations which dates $2^{r}$ B.C. and locat tachyon velocity with respec s.

Ass' sud han's tachyor hypothesis in Einste ariane mass with velocity eqn. we get that ${ }^{[1-,}$, where the moving mass of the tachyon, in $v>c$ an imaginary:

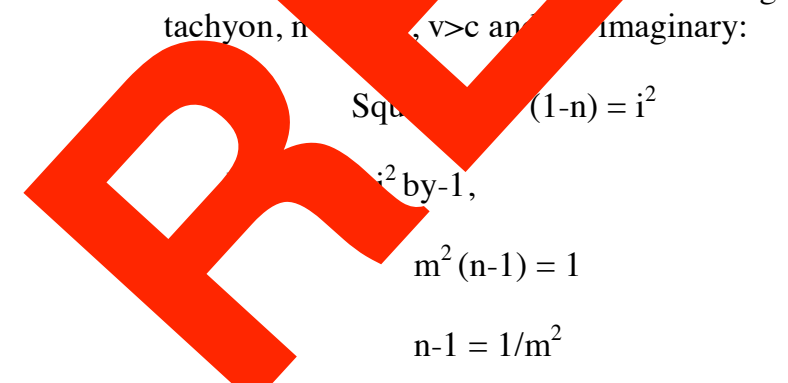

$$
\begin{aligned}
& \mathrm{K}+\mathrm{L}=-\mathrm{b} / \mathrm{a} \\
& \mathrm{KL}=\mathrm{c} / \mathrm{a}
\end{aligned}
$$

Appling (3) and (4) in (2), $\mathrm{K}+\mathrm{L}=1 / \mathrm{m}^{2}, \mathrm{KL}=$ $\left(\mathrm{m}^{2}+1\right) / \mathrm{m}^{2}=-1-1 / \mathrm{m}^{2}$ :

Adding $\mathrm{K}+\mathrm{L}+\mathrm{KL}+1=0$

$$
(\mathrm{K}+1)(\mathrm{L}+1)=0
$$

From (5) we have:

Corresponding Author: M. Sivasubramanian, Department of Mathematics, Mahalingam College of Engineering and Technology, Udumalai Road, Pollachi, Tamil Nadu 642 003, India 


$$
\mathrm{K}=-1
$$

Squaring (1a):

$$
m 4 n^{2}-2 m 4 n+m 4-1=0
$$

Equation 6 is also quadratic in $\mathrm{n}$.

Assuming (3) and (4) in (6), $\mathrm{K}+\mathrm{L}=2 \mathrm{~m} 4 / \mathrm{m} 4=2$ :

$$
\begin{aligned}
& \mathrm{KL}=\mathrm{m} 4-1 / \mathrm{m} 4=1-1 / \mathrm{m} 4 \\
& \text { Adding } \mathrm{K}+\mathrm{L}+\mathrm{KL}=3-1 / \mathrm{m} 4
\end{aligned}
$$

Using (1b) in RHS:

$$
\mathrm{K}+\mathrm{L}+\mathrm{KL}=2-\mathrm{n}^{2}+2 \mathrm{n}
$$

In both the quadratic Eq. 2 and 6 the roots $\mathrm{K}$ and $\mathrm{L}$ denote the velocity of one and the same tachyon. So, putting (5a) in (7) $n^{2}-3-2 n=0$ :

$$
\begin{aligned}
& (\mathrm{n}+1)(\mathrm{n}-3)=0 \\
& \mathrm{n}=-1 \\
& \mathrm{n}=3
\end{aligned}
$$

If we put $n=-1$ in (2) the equation and if we apply $\mathrm{n}=-1$ in $(6)$,

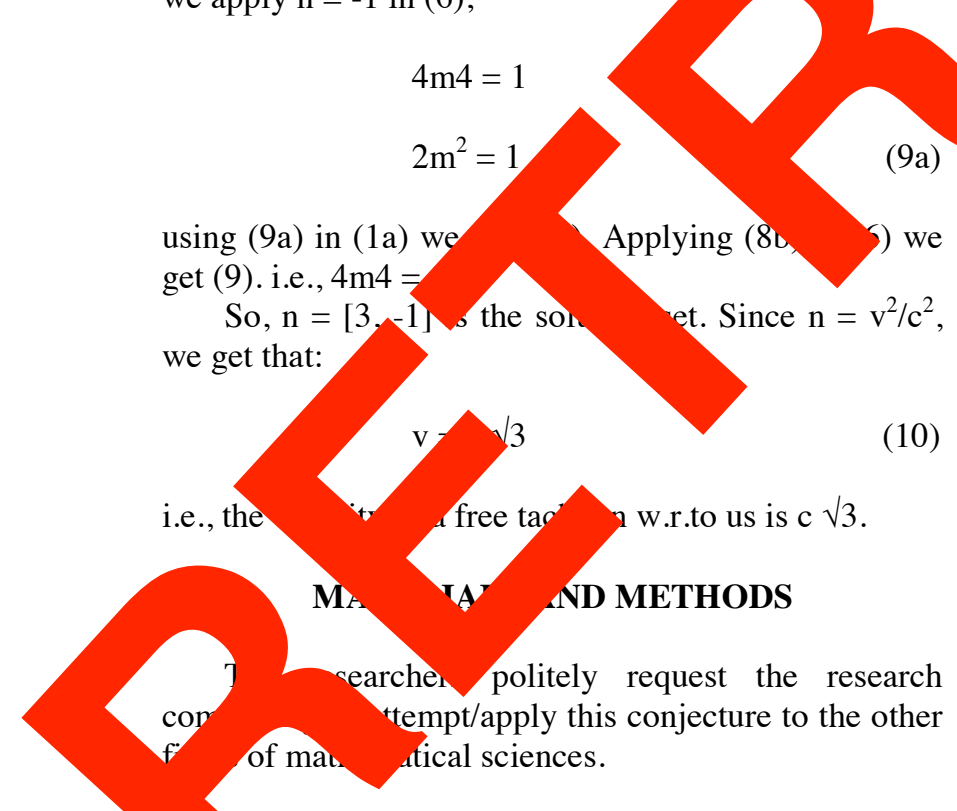

\section{RESULTS AND DISCUSSION}

1. was the Babylonians who gave the solution formula $\mathrm{x}=-\mathrm{B} \pm\left[\mathrm{B}^{2}-4 \mathrm{AC}\right]^{1 / 2}$ for the quadratic Eq. 2 of the general form $\mathrm{Ax}^{2}+\mathrm{Bx}+\mathrm{C}=0$. Quadratic equa an interesting mathematical topic. The membe British parliament had a nice debate on Jup on this topic. Even Einstein's formula E = mc quadratic equation. We can not find th olution the Eq. 2 and 6 by applying the That's why the authors introduc ocal form above hypothesis. Replacing $m \quad \sqrt{2}$ an oy 3 the Eq. 1, 2 and 6 satisfy. So, the acceptable and agreeable.

It is well $\mathrm{k}$

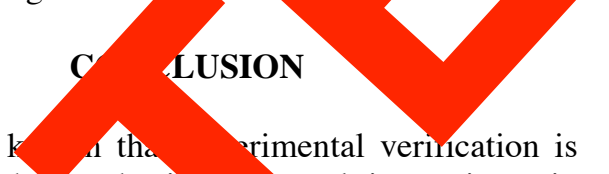
the supreme judge in physic. esult is consistent in theoretical ics, it is consistent in experim oics also. Albert $\downarrow$, tein requested the physi to locate solutions for the burning problems of $\mathrm{pl} \quad \mathrm{s}$ in the easte piritual philosophy. Thripura Rahs is one of th ost famous meta physics in Hindu The great e Thathathreya reveals the existenc this masterpiece. If tachyons are inconsis not easy to derive Eq. 8b. Here it is up to experimental physicists to locate or go. 7 hons.

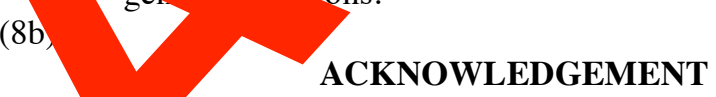

\section{ACKNOWLEDGEMENT}

The researchers wish to thank the management of Mahalingam College of Engineering and Technology, Pollachi, Tamilnadu- 642 003, India for their kind encouragement.

\section{REFERENCES}

1. Bilanuik, O.M.P., V.K. Deshpande and E.C.G. Sudarshan, 1962. Meta relativity. Am. J. Phys., 30: 718-723. DOI: 10.1119/1.1941773

2. William Dunhan, 1990. Journey Through Genius: Great Theorem of Mathematics. 1st Edn., John Wiley and Sons, ISBN: 10: 0471500305, pp: 320.

3. Jones, A., A. Sidney Morris and R. Kenneth Pearson, 1991. Abstract algebra and Famous Impossibilities. 1st Edn., Springer-Verlag, New York, USA., ISBN: 0387976612, pp: 187. 